Manuelle Medizin 2017 · 55:54

DOI 10.1007/s00337-016-0185-9

Online publiziert: 13 . September 2016

๑) Springer-Verlag Berlin Heidelberg 2016

CrossMark

\author{
A. Mizher \\ Dynasom Academy, Konstanz, Deutschland
}

\title{
Rückenbeschwerden lassen sich beseitigen
}

Auch unsere klinische Erfahrung zeigt, dass eine Beinlängendifferenz von $5 \mathrm{~mm}$ zu Meniskus- und Hüftgelenkproblemen führen kann: Das Becken wird gedreht und in eine Fehlstellung gezwungen. Jeder weiß, dass die Füße auf dem Boden in einer Endposition sind. Der Kopf bleibt frei (außer beim Kopfstand) und passt sich an die Gravitation an. Hier übt die Erdanziehungskraft von der Kopfund Oberkörpermasse Kraft in Richtung Boden aus, dies verursacht Axialdruck und zwingt die WS zu unkontrollierten Translationen mit Rotationskomponenten. Dadurch entstehen Scherkräfte und Schäden in allen Bereichen, die an der Haltung und Bewegung der WS beteiligt sind. Die WS kann nicht mehr im Lot bleiben und es kommt dort zu erheblichen Schäden, wie Bandscheibenvorfällen, Skoliosen, Spondylolisthesen und Facettensyndrom, als Folge der Beinlängendifferenzen.

Darum stellen wir fest, dass Beinlängendifferenzen erhebliche Schäden an der WS verursachen. Die Bandscheiben werden ungleichmäßig belastet, die $\mathrm{Fa}$ cettengelenke einseitig abgenützt und die Nerven ständig irritiert. Dadurch persistieren die lokalen und radikulären Schmerzen, bis die Ursache (Beinlängendifferenz und neuromuskuläre Defizite des M.-erector-spinae-Systems) behoben wird.

Unser Konzept vermittelt die gesammelte Erfahrung langjähriger Forschung in der Diagnose und Behandlung von Rückenleiden und nicht die Lösung für alles. Es bleibt Ihnen überlassen, welche Philosophie Sie in Ihrer Praxis verwenden wollen. Am Ende zählen die Ergebnisse.
Ich danke Ihnen für Ihre Aufmerksamkeit und verbleibe mit besten Grüßen

Adnan Mizher

\section{Korrespondenzadresse}

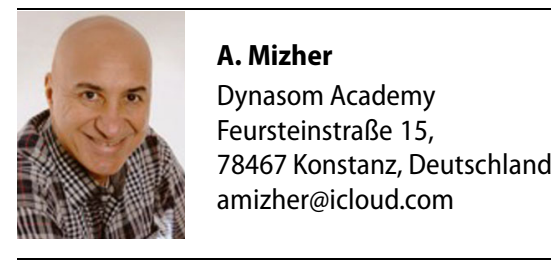

Interessenkonflikt. A. Mizher gibt an, dass kein Interessenkonflikt besteht. 